was a healthy balance expressed between therapeutically positive thinking (such as the family therapies) and recognition of the rights of the child, with much more facility and familiarity with issues of registration, intervention, and actions or procedures to protect children than 10-15 years ago. This balance is exemplified as follows: ". . . in one sense, nearly all the children I see are emotionally abused to some degree . . . but we have a lot of (emotionally) deprived mothers who just are not coping. Some (of these mothers) can be helped, but the prognosis is not too good for others, and we have to think of other supports and interventions on behalf of the child".

A short scrutiny of the numbers shows that formal registration procedures are not netting all the serious child cruelty cases, let alone the mass of apparently less severe ones. The principle reason is that Wiltshire registration now emphasises child protection rather than total numbers. Children thought to be in new (and probably safer) settings, child(ren) with the non-abusive parent, relative or foster carers after the abuse, perpetrators separated or off the scene, these are circumstances which all tend to result in nonregistration. Other reasons include inadequate previous compilation and collation of information, delayed revelations, delayed verifications, and use of psychiatric or family treatment in place of formal procedures when seen as a more manageable option.
The other main conclusion is that a hefty and demanding proportion of child and family guidance work is concerned with treating the consequences of past child abuse in the home, and with breaking the patterns of any continuing harm to children from their carers.

There have been publications linking child psychiatry with child protection (Kennedy, 1988, 1989 and Nicol, 1989), and our obligations in respect of child sexual abuse (Bentovim, 1987). This short study illustrates that a child and family guidance service in the middle of England is not simply an isolated backwater of arcane deliberations but is broadly committed to tackling child abuse by a variety of approaches.

\section{References}

Bentovim, A., Boston, P. \& Van Elburg, A. (1987) Child sexual abuse-children and families referred to a treatment project and the effects of intervention. British Medical Journal, 295, 1453-1457.

KENNEDY, R. (1988) The treatment of child abuse in an in-patient setting. Bulletin of the Royal College of Psychiatrists, 12, 361-366.

(1989) Psychotherapy, child abuse and the law. Psychiatric Bulletin, 13, 471-476.

Nicol, A. R. (1989) The ABC of child abuse: role of the child psychiatry team. British Medical Journal, 299, $451-452$.

\title{
Factors contributing to military casualty rates during war
}

\author{
JaCQueline M. AtKinson, Lecturer in Behavioural Sciences, Department of Public \\ Health, University of Glasgow, 2 Lilybank Gardens, Glasgow G12 8RZ
}

Discussion of psychiatric casualty figures in military personnel tends not to distinguish between acute and chronic conditions. Combat-related stress (CRS) responds well to immediate, short-term intervention. Overall psychiatric casualties are approximately $30 \%$. Contemplating the future in 1982 , Romo \& Schneider suggested casualty figures might be higher. This article considers factors contributing to the incidence of psychiatric casualties.

\section{Military factors affecting number of casualties}

The physical deprivations of war as well as the psychological pressures contribute to problems: battle fatigue is simply that, and is treated with rest and sleep and does not imply other problems.

The incidence of psychiatric combat casualties is directly related to battle intensity. This is most 
commonly gauged by the number of wounded in action (WIA) but a scale based on adequacy of preparation, type of battle, quality of tactical support, strength of enemy and the confidence of the battalion commander in his higher command has been used (Belenky et al, 1987). Other factors regularly seen to affect casualty figures are high morale, leadership and group cohesion. The results of this can be seen in elite troops having lower casualty figures. This indicates that newer unit members, or those who are least like the group are more at risk, including if they become prisoners of war.

If appropriate treatment for CRS is immediately available, the majority (50-85\%) of casualties will return to the unit (Romo \& Schneider, 1982). The attitude of officers seems crucial to this. Inbar and his colleagues (1989) indicated that the "tolerance and acceptance of the commander is ... essential to the successful reintegration of CRS casualties into both military and civilian life following front-line care". They also found that officers were "more severe and less tolerant" to officers showing CRS than to lower ranks, and expected officers to "take more responsibility for their own recovery than simple soldiers" and were less likely to take them back.

The largest group of post-traumatic stress disorder (PTSD) veterans are those from Vietnam with rates from $15 \%$ among male combat veterans in general to $36 \%$ among those exposed to "high war-zone stressor" (Sutner et al, 1990). Of importance in Vietnam were the particular stresses of prolonged guerilla warfare, the occurrence of atrocities and terrorism, language barriers, "the vague military objectives", and failure in debriefing troops returning to the United States. These problems were aggravated by soldiers being rotated in and out of their units every year as a result of infantry troop effectiveness being compromised after three months of battle exposure. The result of this was low cohesion, low morale, increased drug and alcohol abuse, and high numbers of discipline problems. Drug and alcohol abuse both during the war and on return home reflects situational variables and is not reported by, for example, Israeli troops.

Problems in homecoming were exacerbated for the Vietnam veteran by the controversy surrounding the war leading to many experiencing feelings of rejection and isolation. Many of the problems arising with wives and particularly children stem from fighting in a guerilla war where anyone can be the enemy, also making violence and aggression a not uncommon reaction.

In a study of PTSD among prisoners of war from World War II and Korea, Sutner and colleagues (1990) found PTSD correlating with confinement, weight loss, more severe psychological and biological hardship, lower socio-economic status, and lower military rank.

\section{Individual factors}

Factors from the Israeli Defence Force indicate that more intelligent, better educated, better-motivated, younger individuals with a stable personality are the least likely to become psychiatric casualties (Belenky et al, 1987), and in the US low rank and extensive combat experience related to breakdown.

Although one study from Israel indicated that prior combat experience is neither a risk factor nor a protective factor as long as, by the service's own criteria, the soldier was 'combat ready' (which precludes physical and/or mental disability from a previous combat) Solomon et al (1987) reported that soldiers who showed a CRS in earlier wars were at increased risk of PTSD after the 1982 war.

Those who developed PTSD were more likely to have a previous history of truancy from school, poor grades at school, running away from home, fighting, stealing, juvenile police records and parental neglect (Sudak et al, 1984). Two-thirds of PTSD patients had family histories of psychological problems, usually alcoholism, depression and anxiety (Davidson et al, 1985). This may, of course, partly reflect the conscription of certain groups who did not 'draft dodge'. Another finding, however, may have more general implications. PTSD patients had smaller social networks and less social support than did others (Keane et al, 1985).

\section{Medical staff casualties}

Special factors contribute to breakdown of medical and related staffs, including ethical dilemmas, role conflict and ambiguity and sleep deprivation (Brooking, 1983) added to the usual civilian pressures. A large proportion of the Army Medical Services (AMS) are from the Territorial Army and have the additional stress of suddenly being taken from civilian surroundings, their home and family to contend with. PTSD may have special characteristics in medical personnel, "combining the caretaker, combatant and survivor aspects of their experience" (Dewane, 1984). As Brooking sums up: "In some senses the stresses in a medical unit are worse than for a front line soldier. All the trauma of the battle is funnelled through the AMS, who have to support other troops, both physically and emotionally. They deal with the failures of battle, not the successes".

$A$ list of references appears at the end of the next article. 